\title{
„Nachwuchs auf dem Weg in die Freiberuflichkeit begleiten"
}

\author{
Ohne Nachwuchs hat ein Verband keine Zukunft. Der FVDZ hat die Zeichen der Zeit erkannt und \\ die Zahnmedizinstudenten und jungen Berufseinsteiger in den Fokus gerückt. Seit Oktober 2013 \\ kümmert sich Dr. Heike Rump-Schaefer federführend um diesen spannenden Bereich, in dem \\ sich sehr viel bewegt hat.
}

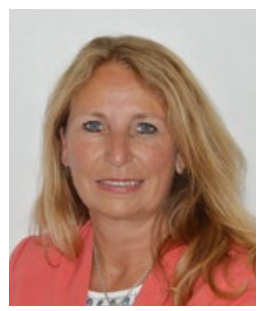

\section{Wo stand der Verband, als Sie den Bereich Nachwuchsarbeit übernommen haben?}

Der Bundesvorstand ist bei der Wahl mit der Intention angetreten, dazu beizutragen, dass junge Zahnärztinnen und Zahnärzte den Mut haben, freiberuflich zu arbeiten. Mir ist es ein Herzensanliegen, die jungen Kollegen dazu nicht nur zu ermuntern, sondern sie auch konkret auf dem Weg zu begleiten.

$\mathrm{Zu}$ Beginn unserer Legislaturperiode gab es in diesem Bereich bereits die Initiative „young dentists“, und es begann gerade die Organisation von Studenten-Workshops.

\section{Was haben Sie in der zurückliegenden Legislaturperiode erreicht?}

Am Anfang unserer Amtszeit haben wir sehr schnell das Mentoring-Programm ins Leben gerufen. Hier vermitteln wir ganz konkret zwischen jungen interessierten Zahnärztinnen und Zahnärzten und den erfahrenen Kolleginnen und Kollegen, die ihren Mentee auf dem Weg in die Freiberuflichkeit begleiten. Das Mentoring-Programm beinhaltet gemeinsame Studienfahrten, auf denen die Nachwuchs-Zahnärzte ihre Mentoren sehr gut kennen lernen. In diesem Vertrauensverhältnis kann das Thema optimal behandelt werden. Unser Ziel ist es, die Vermittlung zwischen potenziellen Praxisübernehmern und Praxisabgebern zu begleiten.

In den vergangenen zwei Jahren wurde deutlich, dass bei uns keine eigenen wirtschaftlichen Interessen im Vordergrund stehen, sondern die Unterstützung der jungen Mitglieder. Das ist die Triebfeder für unser Tun. Ich bin davon überzeugt, dass das Interesse an unseren Programmen auch deshalb stetig wächst. So werden etwa die Studenten-Workshops immer stärker besucht, und immer mehr Studenten nehmen an unseren Kongressen teil. Der FVDZ ermöglicht die kostenlose Teilnahme und bietet individuelle Programmpunkte an. So nimmt der Austausch zwischen den Generationen auf den Kongressen immer mehr Raum ein.

Gerade für die nachwachsende Generation ist es wichtig, frühzeitig Informationen über Themen wie Praxisführung und Abrechnung zu bekommen. Diese Themen gibt es bei uns praxisnah außerhalb des Hörsaals und in Ergänzung zur Assistentenzeit.

Die bereits angesprochene Initiative ,young dentists" hat einen verbesserten Internetauftritt mit neuem Webdesign bekommen. Mit der Optimierung des Zugangs über Tablet-PCs und Smartphones wurden die Kontaktmöglichkeiten ausgeweitet. Dies wird ergänzt durch eine neue Stellenbörse, von der insbesondere junge Mitglieder profitieren. Aber auch erfahrene Praxisinhaber können dort geeignete Nachfolger finden.

\section{Was ist das Ziel für die nächste Wahlperiode?}

Die weitere Ausrichtung unserer Nachwuchsarbeit schlägt sich in neuen Projekten nieder. Sowohl das Projekt „Studium - und was dann?" als auch ein neues Bausteinkonzept, das angehende Zahnmediziner mit dem Rüstzeug für den erfolgreichen Einstieg in die Niederlassung ausstattet, weisen den Weg unserer Nachwuchsarbeit.

Ich engagiere mich mit großer Begeisterung für die Interessen unseres Nachwuchses und freue mich auf die erfolgreiche Weiterentwicklung in diesem Bereich. Das klar formulierte Ziel ist für mich, bei den jungen Kolleginnen und Kollegen neben der fachlichen Kompetenz unternehmerisches Denken und selbstständiges Handeln zu fördern und zu stärken, damit die Freiberuflichkeit unseres Berufsstandes nicht nur für uns als aktive Praxisinhaber, sondern auch in Zukunft für die nachfolgenden $\mathrm{Ge}$ nerationen eine Basis bildet, auf der wir unseren Auftrag der $\mathrm{Pa}$ tientenversorgung in hoher Qualität gerecht werden können.

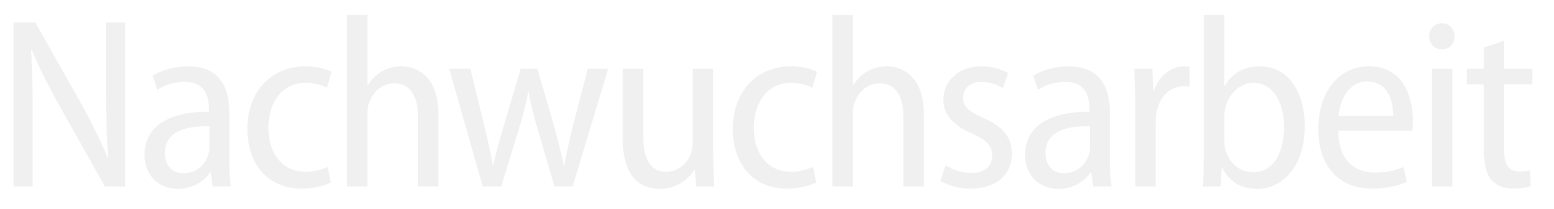

